\title{
ANAP

\section{ÓLEOS SATURADOS: UM ESTUDO DO DESCARTE EM ESTABELECIMENTOS DE TRÊS LAGOAS E ANDRADINA}

Marçal Rogério Rizzo ${ }^{1}$

\section{Stefanni Teodoro Gasparini ${ }^{2}$}

Nayla Furlan da Silva ${ }^{3}$

\begin{abstract}
RESUMO: A proposta deste estudo é identificar as principais características e diferenças no processo de descarte de óleos e gorduras saturadas dos principais restaurantes, lanchonetes e similares localizados nos municípios de Três Lagoas (MS) e Andradina (SP). Metodologicamente, a pesquisa caracteriza-se como estudo descritivo e comparativo, desenvolvido em três etapas. A primeira constitui de pesquisa bibliográfica e documental; a segunda realizou-se por meio de aplicação de questionário estruturado, respondido por representantes das empresas citadas. As questões versaram sobre descarte, conscientização ambiental e informações sobre os estabelecimentos. A última etapa da pesquisa constituiu em entrevistas aos representantes de duas empresas de saneamento básico. Após aplicação e análise dos questionários, notou-se que não houve diferenças tão expressivas entre os dois municípios. Em relação ao descarte final, houve, em ambos os municípios, semelhança nas respostas, sendo que grande porte dos sujeitos respondeu que entregava o óleo e gordura saturados para uma pessoa física, que, por sua vez, os utilizava como matéria-prima para a produção de sabão caseiro.
\end{abstract}

Palavras - Chave: Óleo saturado. Três Lagoas. Andradina. Restaurantes. Lanchonetes.

\footnotetext{
1 Economista, Mestre em Desenvolvimento Econômico, Doutor em Geografia e professor Adjunto da Universidade Federal de Mato Grosso do Sul (UFMS) - Câmpus de Três Lagoas (MS). E-mail: marcalprofessor@yahoo.com.br

${ }_{2}$ Administradora graduada pela Universidade Federal de Mato Grosso do Sul (UFMS) - Câmpus de Três Lagoas (MS). E-mail: stefanni_gt@hotmail.com

3 Administradora graduada pela Universidade Federal de Mato Grosso do Sul (UFMS) - Câmpus de Três Lagoas (MS). E-mail: naah.furlan@hotmail.com
} 


\section{ANAP Brasil \\ ISSN 1904-3240 v. 6, n. 7}

\section{R E V IST A C I E N TÍ F I C A $\quad$ JULHO/2013}

\section{INTRODUÇÃO}

Não há dúvidas de que o homem, em seu processo de produção e consumo, vem causando mudanças profundas no meio ambiente e, consequentemente, no planeta. Pode-se afirmar que o "Homem" vem, por décadas, colocando em risco a existência da vida na Terra. Até pouco tempo, havia certa tolerância em relação às atividades consideradas prejudiciais ao meio ambiente, contudo os temas "sustentabilidade do planeta" e "preservação do meio ambiente" tornaram-se assuntos discutidos e difundidos na mídia, no meio acadêmico, no mundo dos negócios, na maioria das instituições modernas e na sociedade em geral.

No caso do Brasil, até mesmo a Constituição Federal contempla a preservação e conservação ambiental. Observe-se o artigo 225 da Constituição Federal de 1988: "Todos têm direito ao meio ambiente ecologicamente equilibrado, bem de uso comum do povo e essencial à sadia qualidade de vida, impondo-se ao Poder Público e à coletividade o dever de defendê-lo para as presentes e futuras gerações" (CONSTITUIÇÃO FEDERAL, 2010).

Por outro lado, deve-se avaliar qual o volume de recursos extraídos da natureza e a destinação final dos resíduos que são gerados diariamente para atender às necessidades e aos desejos das pessoas. O fato é que a questão ambiental impõe desafios peculiares à gestão e às políticas públicas. Assim, este estudo originou-se do anseio de se conhecer a destinação que vem sendo dada aos óleos e gorduras saturados de estabelecimentos comerciais (como restaurantes, lanchonetes e similares) instalados nas áreas urbanas nos municípios de Três Lagoas (MS) e Andradina (SP).

É plausível argumentar que, mesmo sendo um tema de interesse coletivo, faltamIhe estudos, já que, para parte do meio acadêmico, investigar o destino de óleos e gorduras saturados pode parecer algo irrelevante. Todavia, para o senso comum, despejar óleo e gorduras saturadas na pia, vaso, ralos, córregos, rios, lagoas e mesmo no 


\section{ANAP Brasil \\ ISSN 1904-3240 \\ v. 6, n. 7}

\section{REVISTA C I E N TÍ F I C A JULho/2013}

lixo é algo corriqueiro, uma espécie de prática já consolidada. Assim, fica evidente que se trata de uma temática rica em aspectos a serem explorados.

Uma possível limitação desses argumentos seria a ignorância acerca dos impactos negativos que o óleo e a gordura saturados ocasionam ao meio ambiente e, especialmente, ao ambiente aquático.

Nesse cenário, chama a atenção a falta de foco, uma vez que não se pode protelar ações que visem amenizar os danos ambientais causados pelo óleo e gordura saturados.

Contextualizado o problema, apresenta-se, na seguência, a segunda seção, que consiste na revisão da literatura, considerando os temas: o problema ambiental causado pelo óleo e gorduras saturados e o que pode ser feito com tais resíduos. Já na terceira seção faz-se menção à metodologia utilizada nesta pesquisa. A quarta seção refere-se aos resultados obtidos com a pesquisa de campo. Finaliza-se o artigo proporcionando as considerações finais e recomendações.

\section{REVISÃO DA LITERATURA}

\subsection{O PRoblema ambiental causado pelos óleos e gorduras SATURADOS}

Inicialmente, tentou-se expor de forma clara e nada exaustiva o que são óleos e gorduras saturados. Existem poucos conceitos e definições e praticamente todos se reportam ao mesmo entendimento, de que tende a resultar um sentido bem árido ou duro ao conceito. Conhecidos como óleos alimentares usados (ou simplesmente óleos já utilizados), os óleos e gorduras saturados representam uma categoria de subprodutos ou resíduos provenientes de diferentes atividades e, em sua maior parte, derivados da atividade de fritura de alimentos. Derivam essencialmente do uso de óleos de origem vegetal (azeite, óleo de girassol, óleo de soja, óleo de canola, entre outros). (RIZZO et al, 2013). 


\section{ANAP

Conforme a Agência Nacional de Vigilância Sanitária (ANVISA, 2012), a fritura é uma operação de preparação rápida e confere aos alimentos fritos características únicas de saciedade, aroma, sabor e palatabilidade. Assim, a fritura é um processo necessário na preparação de certos alimentos.

Pode-se dizer, portanto, que, por se tratar de uma das formas mais rápidas de preparo para determinados alimentos, o processo de fritura vem sendo amplamente utilizado, originando grandes quantidades de resíduos do óleo de cozinha - óleo e gordura saturado - em residências, bem como em estabelecimentos comerciais da área de alimentação.

Ao longo da história humana, o desenvolvimento sempre impulsionou transformações de cunho social, cultural, econômico e ambiental. Dobarganes et al (1991) relatam que o consumo de alimentos fritos e pré-fritos tende sempre a aumentar, provocando uma maior ingestão de óleos e gorduras, após terem sido submetidos a elevadas temperaturas em processo de fritura. Constata-se que esse fato tem sido influenciado por razões sociais, econômicas e técnicas, pois as pessoas dispõem de menos tempo para preparação de seus alimentos, tornando o processo de fritura a alternativa mais rápida e prática.

Contemporaneamente, sabe-se que grande parte dos resíduos gerados, tanto nas residências como nos estabelecimentos comerciais do campo gastronômico, é constituída por óleos comestíveis de fritura.

Outro ponto importante a ser ressaltado é apresentado no estudo de O'brien (1998): existe um ponto para o descarte do óleo ou da gordura que ocorre de acordo com a alteração de cor, formação de fumaça e de espuma durante o processo de fritura, além de alterações de aroma e de sabor.

Nesse sentido, o estudo de Silva (2008) fornece a seguinte informação: em estabelecimentos comerciais, a quantidade de óleo utilizada é maior, já que estes usam frigideiras elétricas descontínuas, com capacidades que variam de 15 a 350 litros. Já no caso das indústrias de produção de empanados, salgadinhos e congêneres, o processo de fritura é normalmente contínuo e a capacidade das fritadeiras pode ultrapassar 1000 


\section{ANAP

litros de óleo. Posto isso, uma questão deve ser levada a reflexão, servindo de balizadora deste estudo: Qual é o destino que vem sendo dado aos resíduos - óleos e gorduras saturados - gerados nos estabelecimentos comerciais alimentícios - como restaurantes, lanchonetes e similares?

Santos (2009), citando o trabalho de Castellanelli (2008), apresenta a premissa que norteia este estudo. Relata que o pesquisador que o resíduo do óleo de cozinha, gerado diariamente nos lares, indústrias e estabelecimentos do país, acaba sendo, por falta de informação da população, despejado diretamente nas águas, como em rios e riachos, pias e vasos sanitários, terminando nos sistemas de esgoto. Desse processo resultam danos, como o entupimento dos canos e o encarecimento dos processos de tratamento de esgoto, além da poluição do meio aquático. Outro destino dado aos óleos saturados é o próprio lixo doméstico, contribuindo para o aumento da poluição nas áreas dos aterros sanitários, diminuindo a vida útil desses aterros e colaborando para a formação do gás metano - gás de efeito estufa -, grande fator concorrente para o aquecimento global. Vê-se, assim, a importância deste estudo.

Observa-se que o óleo de cozinha pode provocar impactos ambientais significativos, caso seu descarte seja inadequado. Quando é descartado em córregos, lagos, rios ou até mesmo em mares, cria condições para causar a morte de peixes, seres microscópicos e plantas marinhas. Se descartado em pias e vasos sanitários, provoca entupimentos nas tubulações de residências e estabelecimentos. Em alguns casos, a desobstrução de tubulações necessita do uso de produtos químicos tóxicos o que também é prejudicial ao ambiente. Na rede de esgoto, pode ocasionar infiltração de esgoto no solo, poluindo o lençol freático ou ocasionando refluxo à superfície. Vale lembrar que o óleo saturado pode dificultar e encarecer o tratamento do esgoto.

Nesse sentido, Álvaro Ricardo Calábria Araújo, gerente da Empresa de Saneamento de Mato Grosso do Sul (SANESUL), da Região de Três Lagoas, em entrevista realizada no mês de março de 2012, informou que a rede de esgoto não pode ser vista como depósito de lixo, mas como destino para a água servida em pias, lavatórios e banheiros. Nem mesmo a água da chuva deve ser encaminhada para a rede de esgoto. 


\section{ANAP Brasil \\ ISSN 1904-3240 V. 6, n. 7}

\section{R E V IS TA C I E N T Í F I C A JULho/2013}

Restos de alimentos, papel higiênico e embalagens devem ser jogados no lixo e não no vaso sanitário. O óleo de cozinha, gorduras e graxas jamais deveriam ter como destino final a rede de esgoto. Araújo alertou para o risco de que estes fiquem incrustados no encanamento e interrompam o fluxo de esgoto, causando dano à rede. Lembrou, também, que todo cidadão quer o esgoto longe de sua casa, porém muitos não se preocupam em tomar alguns cuidados para que não vaze. "Quando ocorre vazamento do esgoto, devido a entupimento, o mesmo pode voltar para dentro da casa da pessoa, necessitando fazer limpeza, desinfecção. Já ocorreu de ser necessário colocar os moradores em hotel para realizar a limpeza."

Araújo destacou, ainda, que há casos em que o óleo de cozinha, gorduras e graxas podem interromper as bombas existentes na rede de esgoto e prejudicar 0 trabalho de tratamento, pois seus excessos prejudicam a degradação da matéria orgânica feita por bactérias.

Nesse contexto, para Araújo, parte da solução poderia vir de parcerias entre as empresas de saneamento básico, o Ministério Público Estadual (Promotorias de Meio Ambiente), as câmaras municipais e prefeituras, mediante elaboração de leis e formas de fiscalização, obrigando os estabelecimentos comerciais que atuam especialmente no ramo alimentício a fazerem a coleta seletiva dos óleos e gorduras saturados. Assim, estes teriam o destino adequado e serviriam como matéria-prima para sabão e biodiesel.

Araújo acrescentou que visando ao engajamento do cidadão comum a SANESUL vem realizando palestras e concursos com premiação junto à Secretária Estadual de Educação para conscientizar e educar crianças e jovens, uma vez que a empresa não tem o "poder de polícia" para obrigar o não lançamento de óleos e gorduras saturados na rede. No ano de 2012, o tema central do concurso foi justamente ações que inibam o lançamento de óleo e gorduras saturados na rede de esgoto. A Caixa Econômica Federal tem sido a financiadora das obras de saneamento do Brasil e é quem faz a doação dos prêmios nos concursos mencionados.

Similarmente, na visão de Antonio Rodrigues da Grela Filho, Superintendente da Unidade de Negócio do Baixo Tietê e Grande da Companhia de Saneamento Básico do 


\section{ANAP

\section{REVISTA C I E N TÍ F I C A JULHO/2013}

Estado de São Paulo (SABESP), em entrevista concedida em abril de 2012, o lançamento de óleo e gordura saturados na rede de esgoto pode tornar-se um enorme problema, pois esse material se incrusta no ramal predial e na rede coletora, provocando sua obstrução. O óleo, quando lançado na rede, cria uma massa de gordura que vai endurecendo. Com a incrustação, ocorre a obstrução, que ocasiona o retorno do esgoto nos imóveis que estão acima do local do entupimento e ainda prejudica o tratamento do esgoto coletado, pois aumenta a demanda bioquímica de oxigênio $(\mathrm{DBO})^{4}$ na estação de tratamento.

Para Grela Filho, parte desse problema pode ser amenizada quando se trabalha educando e conscientizando ambientalmente a população e os empresários. O correto seria desenvolver campanhas de coleta do óleo e gordura saturados, a fim de impossibilitar o seu lançamento nas redes de esgoto. Esse trabalho deveria ser feito em parceria com escolas, entidades, instituições, ONGs e outros.

Grela Filho ressaltou, ainda, que a região do Baixo Tietê e Grande do Estado de São Paulo já possuem algumas entidades que estão coletando esse material, vendendo, transformando-o em recursos para manutenção geral. Já outras entidades utilizam o óleo saturado para a produção de sabão caseiro. O fato é que o óleo pode e deve ser reaproveitado e jamais lançado na rede de esgotos ou no lixo.

\subsection{O QUE FAZER COM O ÓLEO SATURADO?}

Acredita-se que é importante compreender o descarte de óleos e gorduras saturados pelo viés de seu reuso. Assim, nesta seção focaliza-se a lógica existente a partir do retorno desses resíduos ao ciclo produtivo, já que se forma um ciclo sustentável, diminuindo a extração de recursos naturais e evitando a poluição, em especial das águas e do solo.

Para Pitta Júnior (2012), as principais formas de reaproveitamento de óleos e gorduras saturados são de uma maneira geral, produção de glicerina, padronização para

\footnotetext{
${ }^{4}$ A DBO representa o potencial ou a capacidade de uma massa orgânica "roubar" o oxigênio dissolvido nas águas. Esse "roubo" não é, todavia, praticado diretamente pelo composto orgânico; é resultado da atividade de micro-organismos que se alimentam da matéria orgânica. (Sítio eletrônico do Ambiente Brasil).
} 


\section{ANAP

composição de tintas, produção de massa de vidraceiro, produção de farinha básica para ração animal, geração de energia elétrica por meio de queima em caldeira, produção de biodiesel, obtendo-se glicerina como subproduto. Turtelli (2010) comunga da mesma visão, apontando como reusos desse resíduo a fabricação de biodiesel, sabão, tintas, vernizes, massa de vidraceiro e ração para uso animal.

O biodiesel é tido como uma alternativa de energia renovável. Apesar de vastamente discutido como uma nova opção, existem poucos trabalhos acadêmicos com objetivos semelhantes aos desta pesquisa. Num desses, Costa Neto (2000) apresenta o óleo de soja usado em frituras como biocombustível alternativo ao óleo diesel. À luz dessa realidade, diversos pesquisadores seguem a mesma linha, entre os quais se podem citar os estudos de Christoff (2007); Tickell (1999); Turtelli (2010) e Barbosa et al (2010).

O que fica claro é que reutilizar o óleo e a gordura saturados apresenta vários pontos positivos. Das contribuições, destaca-se: menor custo para obtenção da matériaprima; geração de empregos e renda na coleta, benefício e transformação da matériaprima em produto final; redução dos custos de tratamento do esgoto; diminuição dos custos com manutenção da rede de esgoto; queda no número de ocorrências de entupimento dos canos da rede de esgotos; e, por fim, ganhos ambientais, uma vez que se evita a poluição das águas e do solo.

É importante enfatizar que, antes da reutilização do óleo e gordura saturados, existe um ponto crucial que merece destaque: a importância de se informar a população sobre formas adequadas de descarte desses resíduos. Não obstante, ao que tudo indica, atualmente no Brasil ainda existem poucas redes eficientes de coleta seletiva de tais produtos, portanto o problema ambiental permanece.

\section{PROCEDIMENTOS METODOLÓGICOS}

\subsection{CARACTERIZAÇÃO DO MÉTODO DA PESQUISA}

A investigação que originou este trabalho caracterizou-se como estudo descritivo (Richardson,1989; e Gil, 2002), pois levantou as características e possíveis diferenças do 


\section{ANAP

descarte dos óleos e gorduras saturados produzidos pelos principais estabelecimentos comerciais do ramo de alimentação localizados nos municípios de Três Lagoas (MS) e Andradina (SP). Na visão de Gil (2002), as pesquisas descritivas têm como objetivo analisar características, levantar opiniões, atitudes e crenças de determinada população. Enquadra-se como uma pesquisa qualitativa, já que o foco não foi apresentar índices ou números.

\subsection{DESCRIÇÃO DAS ÁREAS DE ESTUDO}

Três Lagoas é um município da região Centro-Oeste, localizado no extremo leste do Estado de Mato Grosso do Sul (MS), divisa com o Estado de São Paulo. Atualmente, trata-se do terceiro município mais populoso e importante de MS. De acordo com o sítio eletrônico da Prefeitura Municipal de Três Lagoas, o núcleo urbano está localizado a 340 km da capital do Estado, Campo Grande. Possui uma área territorial de 10.206,95 Km² e conta com uma população de aproximadamente 102 mil habitantes.

Os municípios limítrofes são: Água Clara (Oeste); Brasilândia (Sul); Inocência (Norte), Selvíria (Norte) e Castilho (Leste) - município do Estado de São Paulo (conforme mapa 1 que segue abaixo). 


\section{ANAP Brasil ISSN 1904-3240 V. 6, n. 7}

\section{REVISTA C I E N T ÍF I C A JULho/2013}

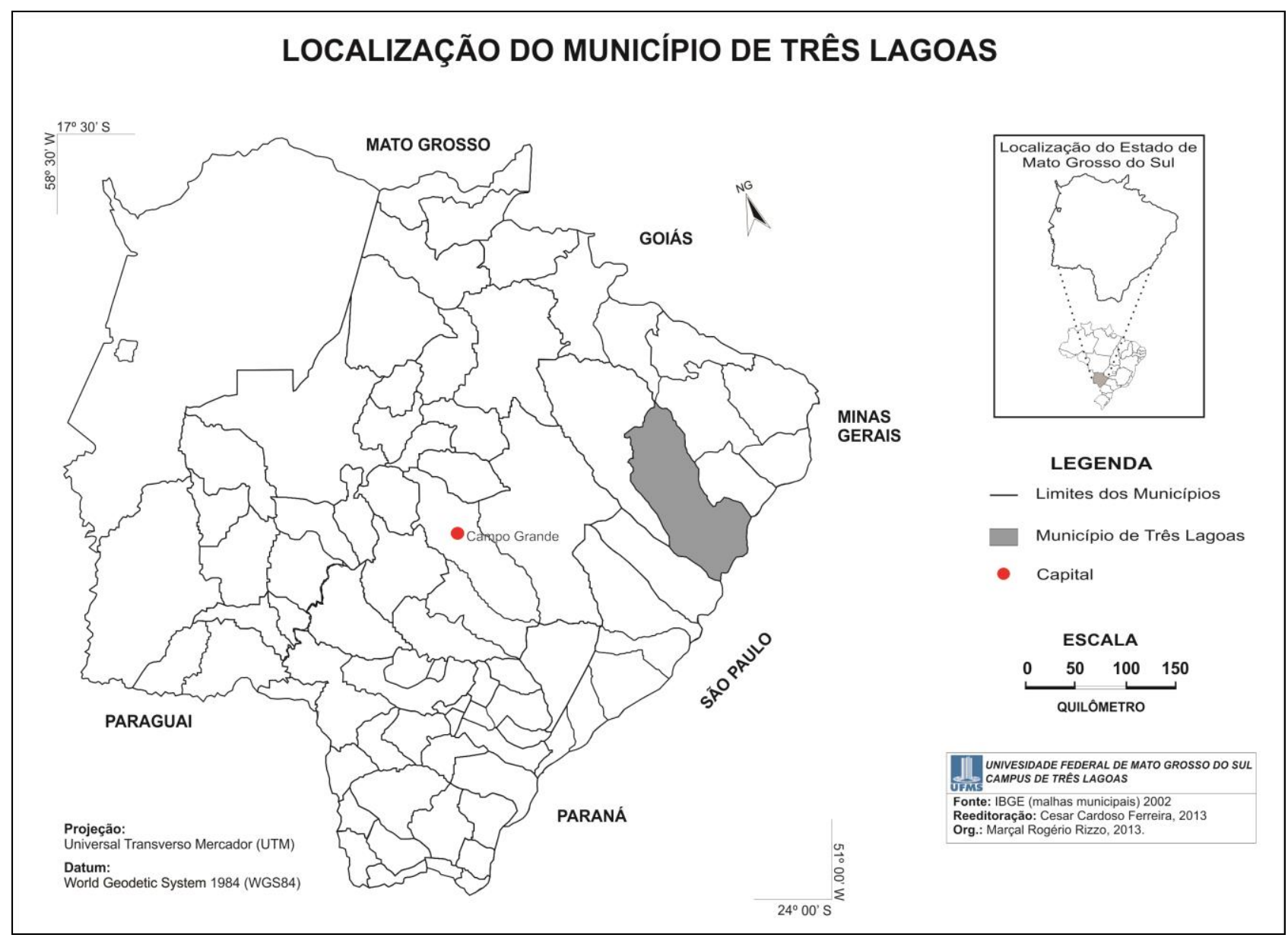

Mapa 1 - Localização do Município de Três Lagoas (MS).

De acordo com Correa (1999), as terras hoje pertencentes à cidade de Três Lagoas eram habitadas inicialmente por índios, contudo foram desbravadas e ocupadas, inicialmente, por aventureiros paulistas (bandeirantes) em reconhecimento do território nacional e busca de novas áreas para a pecuária extensiva.

Três Lagoas foi fundada no início do século XX, por Antônio Trajano dos Santos, e seu nome surgiu devido à topografia da cidade: observam-se três lagoas situadas no perímetro suburbano da cidade. Surge, também, mais um estímulo ao desenvolvimento: a chegada dos trilhos da estrada de ferro noroeste do Brasil.

Nos últimos anos, o município vem se destacando como a capital mundial da celulose. Em matéria realizada sobre o município de Três Lagoas, a revista "Época 


\section{ANAP

\section{R E V I S T A C I E N T Í F I C A JULHO/2013}

Negócios" aponta que "Três Lagoas - Capital mundial da celulose [...] De capital brasileira de gado, a cidade está se transformando na metrópole global da celulose [...]", projetando que, a partir de 2014, o município produzirá mais de 4,3 bilhões de toneladas de celulose, por intermédio dos projetos das fábricas Fibria e Eldorado Brasil. (SPOTORNO, 2010, p.139).

Segundo o sítio eletrônico da Prefeitura Municipal do segundo município onde se aplicou a pesquisa de campo, Andradina é um município localizado no Estado de São Paulo, mais precisamente na mesorregião de Araçatuba e microrregião de Andradina. Conta hoje com uma área territorial de $964,19 \mathrm{Km}^{2}$ e com uma população de pouco mais de 55 mil habitantes. O núcleo urbano está localizado a $630 \mathrm{~km}$ da capital do Estado de São Paulo, ou seja, a cidade de São Paulo.

Tem como municípios limítrofes: Nova Independência; Castilho; Itapura; Pereira Barreto; Guaraçaí, Murutinga do Sul e llha Solteira, conforme ilustra mapa 2. 


\section{ANAP \\ Brasil \\ ISSN 1904-3240 \\ V. 6, n. 7}

\begin{tabular}{llll}
\hline REV I S T A & C I E N T Í F I C A & JULho/2013 \\
\hline
\end{tabular}

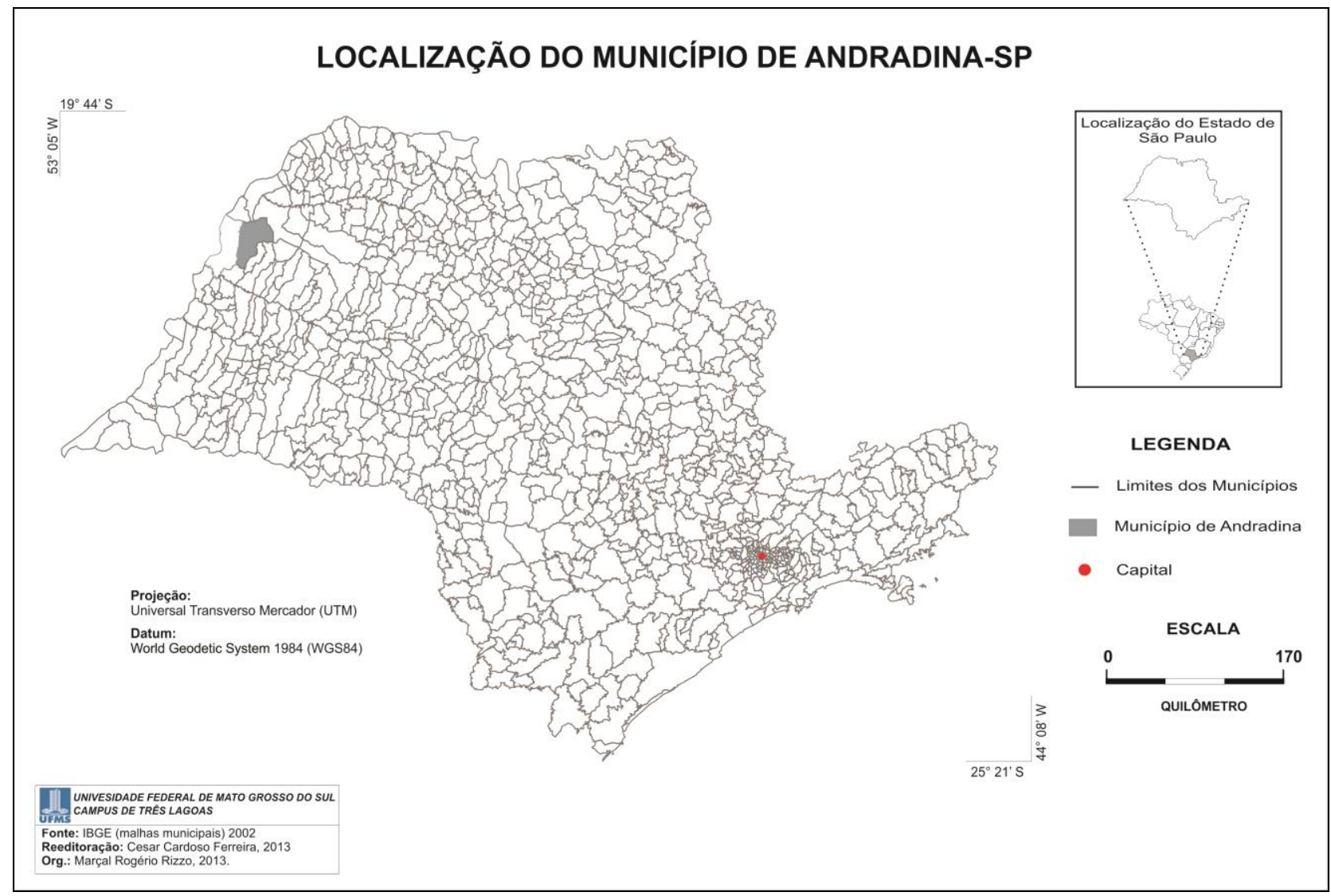

Mapa 2 - Localização do Município de Andradina (MS).

O município foi fundado no ano de 1932, pelo fazendeiro Antonio Joaquim de Moura Andrade, conhecido como o maior criador de gado do Brasil, de que deriva o conhecido epíteto "Terra do Rei do Gado", em homenagem a seu fundador, que loteou parte de sua fazenda Guanabara em pequenos sítios, vendendo-os em condições facilitadas para povoar Andradina.

Houve um surto de malária, com o avanço da estrada de ferro noroeste do Brasil, em direção ao rio Paraná, dificultando a fixação dos povoadores. Mesmo assim, formaram-se muitas fazendas para a exploração de madeira. Rapidamente, a exploração foi substituída pela policultura. No ano de 1936, fez-se a transição de cerealista para a monocultura de algodão, mas, em virtude da terra "fértil" para capim, a pecuária tornou-se mais vantajosa. 


\section{ANAP

\section{R E V I S T A C I E N T ÍF I C A}

Atualmente, o município continua com sua economia ligada ao setor agropecuário. De acordo com Lopes e Almeida (2013), Andradina é um município pertencente a uma região que se tem destacado pelas diversas reivindicações por terra dentro do Estado de São Paulo, sendo um dos principais pontos do Brasil em projetos de assentamentos de Reforma Agrária.

\subsection{UNIVERSO E AMOSTRA}

O universo da pesquisa é formado pelos principais estabelecimentos comerciais do ramo alimentício, em especial os principais restaurantes; lanchonetes e similares localizados nos municípios de Três Lagoas (MS) e Andradina (SP).

Aplicaram-se, no decorrer dos meses de agosto e setembro de 2012, em 25 estabelecimentos comerciais alimentícios questionários contendo questões fechadas. Ressalta-se que a escolha dessas cidades obedeceu aos critérios de proximidade, 0 pertencimento a diferentes estados da federação e representatividade no ramo.

Evidencia-se que a pesquisa baseou-se numa amostra não probabilística. Segundo Mattar (2005, p. 157), "não é conhecida a probabilidade de cada elemento fazer parte da amostra", de modo que, não permite controle sobre o erro amostral e não aceita a generalização dos dados obtidos para a população. Optou-se por utilizar a amostragem não probabilística pelas dificuldades na elaboração do estudo, como limitação de tempo, restrição de recursos financeiros e humanos. Acrescenta-se que as próprias prefeituras não têm um controle sobre o número exato de restaurantes, lanchonetes e similares nos municípios pesquisados.

Os questionários foram divididos em 4 seções: variáveis demográficas do entrevistado; informações sobre o estabelecimento comercial; informações sobre o uso e destinação do óleo e gordura; informações sobre a conscientização e a educação ambiental no município.

\subsection{PROCEDIMENTOS DE PESQUISA}




\section{ANAP Brasil \\ ISSN 1904-3240 V. 6, n. 7}

\section{R E V I S T A C I E N TÍ F I C A JULHO/2013}

Considerados os procedimentos utilizados, classifica-se como uma pesquisa básica, tendo por objetivo colher informações relacionadas à proposta central do estudo.

A coleta de dados ocorreu em três etapas: primeiramente, realizou-se um levantamento bibliográfico/webbliográfico e documental, para a elaboração da fundamentação teórica, base de sustentação deste trabalho. De acordo com Cervo e Bervian (2002, p.65), a pesquisa bibliográfica "é feita com o intuito de recolher informações e conhecimentos prévios acerca de um problema para o qual se procura resposta ou acerca de uma hipótese que se quer experimentar". Foram consultados livros, teses de doutoramento, dissertação de mestrado e artigos publicados em anais de congressos, além de revistas e jornais. A pesquisa bibliográfica e documental priorizou temas como: óleos e gorduras saturadas; dados e informações sobre Três Lagoas e Andradina. Em seguida, foram realizadas entrevistas semiestruturadas junto aos representantes das empresas de água e saneamento básico (SANESUL e SABESP). As entrevistas foram gravadas e transcritas na íntegra. Por fim, as autoras S.T.G e N.F.S aplicaram questionários a representantes dos principais estabelecimentos comerciais localizados nas duas cidades. Após a coleta de dados, efetuou-se a tabulação dos dados.

\section{RESULTADOS DA PESQUISA}

Os dados da pesquisa foram tabulados e geraram informações que serviram de base para a comparação entre os estabelecimentos comerciais localizados em ambos os municípios.

\subsection{ESTABELECIMENTOS LOCALIZADOS EM TRÊS LAGOAS (MS)}

Examinadas as variáveis demográficas, constatou-se que 16 dos 25 entrevistados de Três Lagoas são homens e têm mais de 40 anos, possuindo o $2^{\circ}$ grau incompleto. Já 0 rendimento salarial destes entrevistados está entre $R \$ 1.000,00$ e $R \$ 2.000,00$. Ainda 12 


\section{ANAP Brasil \\ ISSN 1904-3240 v. 6, n. 7}

\section{R E V I S T A C I E N T Í F I C A JULHO/2013}

dos 25 entrevistados começaram o negócio informalmente e este está em funcionamento há mais de 15 anos, atendendo diariamente mais de 150 pessoas. Constatou-se que uma parte considerável dos estabelecimentos "nasceu" na informalidade - quase 50\% dos estabelecimentos pesquisados -, tendo a própria família como colaboradores.

Constatou-se a necessidade de uma quantidade significativa do óleo de cozinha, a saber, de 1 a 3 litros/dia. Quanto ao tipo de óleo utilizado, mais de 70\% dos entrevistados responderam que preferem óleo vegetal e, eventualmente, utilizam a gordura hidrogenada. De todo esse material usado, em média mais de 13 litros são descartados semanalmente por estabelecimento, sendo 55\% doados, na maioria das vezes, para pessoas físicas não identificadas, de forma descontínua, objetivando a produção de sabão caseiro. Sob a circunstância de o óleo já saturado não possuir valor considerável, prevalece a opção pela doação, sem planejamento. Atualmente, esse resíduo é visto como um problema.

Dos 25 entrevistados, 24 afirmaram ter consciência de que o descarte incorreto pode trazer danos ao meio ambiente, bem como sérios problemas nas redes de esgoto dos municípios, caso os resíduos sejam lançados em pias ou vasos sanitários.

Com relação ao apoio do poder público do município ao descarte correto, 48\% não sabem se já houve ou há alguma campanha nesse sentido, entretanto $56 \%$ afirmaram que ações responsáveis de descarte somente ocorreriam com um incentivo fiscal ou financeiro.

Também se pôde verificar que a maior parte dos entrevistados participaria de um programa permanente de coleta do óleo saturado de seu estabelecimento caso o programa do município fosse bem divulgado.

\subsection{ESTABELECIMENTOS LOCALIZADOS EM ANDRADINA (SP)}

Os dados da pesquisa de campo apontaram que, na cidade de Andradina, $52 \%$ dos gestores dos restaurantes, lanchonetes e similares são homens e 48\% mulheres, na faixa etária de 20 a 50 anos. Dentre eles, apenas um administrador concluiu o ensino superior 


\section{ANAP

e a maioria conta com uma renda menor que $R \$ 1.000,00$. Vale ressaltar que a maior parte dos estabelecimentos é de pequeno porte.

Diferentemente de Três Lagoas, uma minoria dos estabelecimentos iniciou suas atividades na informalidade. Apenas um estabelecimento está no ramo há mais de 20 anos; nove, entre 1 e 3 anos; cinco, entre 3 e 10 anos, e sete estão no ramo há menos de 1 ano. Um fator considerável é que, no dia a dia, esses estabelecimentos atendem cerca de 70 clientes, tendo um faturamento mensal bruto entre $R \$ 5.000,00$ e $R \$ 10.000,00$.

Em relação ao descarte dos resíduos, $97 \%$ dos entrevistados responderam que os armazenam em garrafas e que usam diariamente cerca de 3 litros, descartando semanalmente entre 3 e 15 litros, em forma de doação a pessoas físicas. Para 10\% dos entrevistados, a doação é feita a uma escola do município, sendo os beneficiados pessoas físicas que fabricam sabão caseiro.

Notou-se que há uma imprecisão entre a quantidade de óleo utilizada diariamente e o descarte que é feito semanalmente. Em tese, isso pode ser explicado, uma vez que os entrevistados são gerentes ou proprietários e não atuam diretamente na cozinha e no descarte do óleo saturado. Vale destacar que caso o óleo saturado fosse vendido tendo um valor de mercado considerável, existiria uma atenção maior por parte dos gestores.

Todos os entrevistados afirmaram estar conscientes do problema que o descarte incorreto ocasiona. A maioria acredita que os estabelecimentos que agem de maneira não responsável, o fazem por falta de informação. Esse problema poderia ser solucionado com o uso de incentivos fiscais e por meio de recolhimento por ONGs que contam com algum programa de coleta. A maioria afirmou que doaria o óleo saturado.

\section{CONSIDERAÇÕES FINAIS E RECOMENDAÇÕES}

A proposta desta pesquisa foi conhecer as principais peculiaridades e diferenças no processo de descarte de óleos e gorduras saturadas realizado pelos principais restaurantes, lanchonetes e similares de Três Lagoas e Andradina. Sem a pretensão de 


\section{ANAP

esgotar o tema ou de esclarecer polêmicas a seu respeito, optou-se por um estudo descritivo e eminentemente qualitativo.

Após a realização da pesquisa, constatou-se que é unanimidade entre os entrevistados o fato de que lançar o óleo ou gordura saturados em pias, vasos sanitários e ralos traz danos para a rede de esgotos.

Mesmo não tendo pesquisado a totalidade dos restaurantes, lanchonetes e similares de Três Lagoas e Andradina, os resultados alcançados permitem afirmar que os entrevistados têm consciência de que o descarte de óleos e gorduras saturados é um problema ambiental grave. Portanto, o descarte do óleo e gordura em local inadequado não ocorre por desconhecimento.

Além disso, a maior parte dos entrevistados, de ambos os municípios, afirmou que faz doações de forma descontínua e informal a pessoas físicas para a produção de sabão artesanal.

A pesquisa permitiu identificar que, em Três Lagoas, ao contrário de Andradina, há uma maior organização e existência de programas e campanhas - mesmo que recentes - de coleta seletiva de óleos e gorduras saturados. Há também um trabalho de coleta de óleo para reaproveitamento na produção de biodiesel articulado pelo Rotary Club Cidade das Águas - que merece um estudo mais detalhado.

Cabe considerar uma importante limitação deste trabalho. Não foi possível entrevistar diretamente os colaboradores que atuam na cozinha dos estabelecimentos comerciais do ramo alimentício, o que poderia fornecer maiores detalhes a respeito do descarte dos resíduos e de consciência ambiental.

Conclui-se, com base nos resultados obtidos, que é necessária uma mudança de cultura populacional, empresarial e governamental em relação ao descarte do óleo e gorduras saturados. Sugere-se, destarte, a realização de campanhas de educação e conscientização ambiental junto aos estabelecimentos comerciais e à própria população em ambas as cidades. Consequentemente, a tendência de apóio a programas de coleta de óleo e gordura seria maior. 


\section{ANAP

\section{R E V I S T A C I E N T Í F I C A $\quad$ JULHO/2013}

Finalmente, a título de proposta, sugere-se a necessidade de realização de outros estudos que aprofundem análises do descarte de óleos e gorduras saturados, especialmente em residências, buscando diagnosticar e, quiçá, trazer possíveis soluções para amenizar o problema da poluição que tais resíduos ocasionam ao meio ambiente.

\section{AGRADECIMENTOS:}

Os autores agradecem ao senhor Álvaro Ricardo Calábria Araújo, gerente da Empresa de Saneamento de Mato Grosso do Sul (SANESUL), da Região de Três Lagoas, e ao senhor Antonio Rodrigues da Grela Filho, Superintendente da Unidade de Negócio do Baixo Tietê e Grande da Companhia de Saneamento Básico do Estado de São Paulo (SABESP), pelas informações fornecidas para a realização deste trabalho. Agradecem ainda, o geógrafo da UFMS - campus de Três Lagoas, Cesar Cardoso Ferreira, pela reeditoração dos mapas que estão neste artigo.

\section{REFERÊNCIAS}

AMBIENTE BRASIL. A importância da DBO. Disponível em: $<$ http://ambientes.ambientebrasil.com.br/agua/impactos_sobre_as_aguas/a_importancia_ da_dbo.html> Acesso em: 10 fev. 2013.

ANDRADINA (Município). Sobre a cidade. Disponível em: <http://www.andradina.sp.gov.br> Acesso em: 20 fev. 2013.

BARBOSA, G. B.; PASQUALETTO, A. Aproveitamento do óleo residual de fritura na produção de biodiesel. In: PASQUALETTO, A.; GARBELINI, S. M. MP ouve a academia: considerações técnicas à atuação ambiental. Goiânia: Ministério Público de Goiás, ESMP, 2010.

BRASIL. Constituição Federal. Brasília. Senado Federal, 2010.

BRASIL. AGÊNCIA NACIONAL DE VIGILÂNCIA SANITÁRIA (ANVISA). Informe Técnico no 11, de 5 de outubro de 2004. Assunto: óleos e gorduras utilizados em frituras. Disponível em: <http://www.anvisa.gov.br/alimentos/informes/11_051004.htm>. Acesso em: 06 mai. 2012. 


\section{ANAP

CASTELLANELLI, C. A. Estudo da viabilidade de produção do biodiesel, obtido através do óleo de fritura usado, na cidade de Santa Maria - RS. 2008. 92f. Dissertação (Mestrado em Engenharia de Produção) Universidade Federal de Santa Maria, Santa Maria, RS.

CERVO, A. L.; BERVIAN, P. A. Metodologia científica. 5. ed. São Paulo: Makron Books, 2002.

CORREA, V. B. Fronteira oeste. Campo Grande/MS: Editora UFMS, 1999.

COSTA NETO, P.R; ROSSI, L.F Santos; ZAGONEL, G; RAMOS, L. Produção de biocombustível alternativo ao óleo diesel através da transesterificação de óleo de soja usado em frituras. In: Revista Química Nova, Curitiba/PR, n. 23, ano IV, p. 531-537. 2000.Química Nova, 23(4), 2000, p. 531- 537.

CHRISTOFF, P. Produção de biodiesel a partir do óleo residual de fritura comercial estudo de caso: Guaratuba, litoral paranaense. 2007. 82f. Dissertação (Mestrado em Desenvolvimento de Tecnologias) Instituto de Engenharia do Paraná (IEP), Curitiba, PR.

DOBARGANES, M. C.; PÉREZ-CAMINO, M. C. Frying process: selection of fats and quality control. International Meeting on Fats \& Oils Technology Symposium and Exhibition. p. 58-66, 1991.

GIL, A. C. Como elaborar projetos de pesquisa. 4. ed. São Paulo: Atlas, 2002.

IBGE - INSTITUTO BRASILEIRO DE GEOGRAFIA E ESTATÍSTICA. Cidades@. Disponível em: <http://www.ibge.gov.br/cidadesat/topwindow.htm?1> Acesso em: 10 abr 2012.

LOPES, D. E.; ALMEIDA, R. A. Avaliação do Programa de Aquisição de Alimentos (PAA) e do Programa Nacional de Alimentação Escolar (PNAE) nos municípios de Castilho e Andradina-SP. Revista Pegada Eletrônica, Presidente Prudente, vol. 13 n.1, Disponível em: <http://revista.fct.unesp.br/index.php/pegada/article/view/1036/1906>. Acesso em: 20 abr. 2013.

MATTAR, F. N. Pesquisa de marketing. 6. ed. São Paulo: Atlas, 2005.

O'BRIEN, R. D. Fats and oils: formulating and processing for applications. Lancaster: Technomic Publishing, p. $385-410,1998$. 


\section{ANAP

PITTA JÚNIOR., O. S. R. et al. Reciclagem do óleo de cozinha usado: uma contribuição para aumentar a produtividade do processo. 2nd International Workshop Advances in Cleaner Production São Paulo: 20 a 22 mai. 2009. Disponível em: <http://www.advancesincleanerproduction.net/second/files/sessoes/4b/2/M.\%20S.\%20Nog ueira\%20-\%20Resumo\%20Exp.pdf>. Acesso em: 13 abr. 2012.

RICHARDSON, R. J. Pesquisa social: métodos e técnicas. São Paulo: Atlas, 1989.

RIZZO, M. R.; GASPARINI, S. T.; SILVA, N. F. Óleo saturado e o problema ambiental. Diário Noroeste. Colatina ES, 02 e 03 mar. 2013.

SANTOS; R. S. Gerenciamento de resíduos: coleta de óleo comestível. São Paulo. 2009. 52f. Monografia (Tecnologia em Logística) - Faculdade de Tecnologia da Zona Leste. São Paulo, SP.

SILVA, L. L. Estudo de óleos residuais oriundos de processo de fritura e qualificação desses para obtenção de monoésteres (Biodiesel). $2008.52 f$. Dissertação (Mestrado em Engenharia Química) Universidade Federal de Alagoas, Maceió, AL.

SPOTORNO, K. Três Lagoas - Capital mundial da celulose. Época Negócios. São Paulo, SP, no. 44, p. 138-151, outubro. 2010.

TICKELL, J.C., From the fryer to the fuel tank: how to marke cheap, clean fuel from used vegetable oil. 2. ed. Sarasota-FL: Green Teach Publishing, 1999.

TRÊS LAGOAS (Município). Desenvolvimento Econômico - Conheça nossas potencialidades. Disponível em:<http://www.treslagoas.ms.gov.br> Acesso em: 20 fev. 2013.

TURTELLI, C. Reciclagem do óleo residual de cozinha: ações governamentais e comunitárias. Bauru, SP: Editora Thangka, 2010. 